\title{
SOCIOLOGIA ECONÔMICA
}

N as últimas duas décadas a sociologia econômica tem se mostrado um campo promissor e em expansão. Alguns autores a definem como a aplicação de estruturas de referência, variáveis e modelos sociológicos a atividades complexas relacionadas à produção, distribuição, troca, consumo de bens e serviços escassos. 0 crescente interesse pela área se verifica em tor- no do debate entre economistas e sociólogos, mais precisamente entre a economia neoclássica e as ciências sociais. Ana C ristina Braga Martes, professora titular da FVG-EAESP, e Maurício C. Serafim, doutorando em Administração de Empresas na FGVEAESP, recomendam os seguintes livros na área de sociologia econômica:

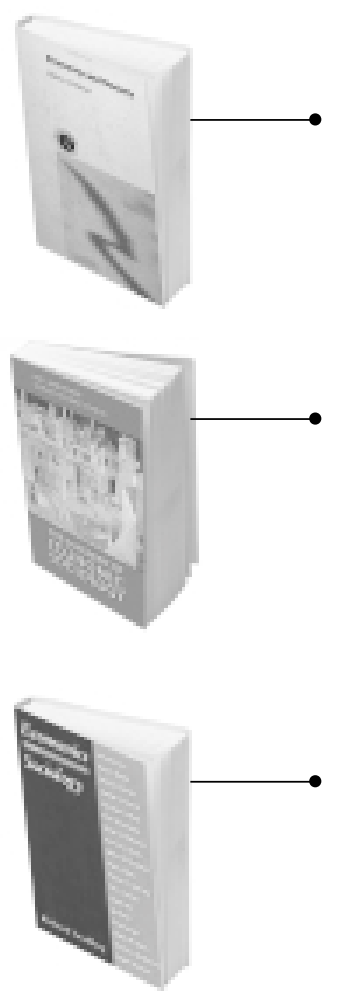

ECONOMY AND SOCIETY. Robert J. Holton London: Routledge, 1992.289 p.

Holton argumenta que os arranjos políticos e culturais influenciam o funcionamento da vida econômica, na mesma medida em que os fatores econômicos influenciam a cultura e a política. Em seguida, o autor analisa aspectos da história do pensamento econômico e social, abarcando desde o liberalismo econômico até as teorias mais recentes sobre "imersão social da economia" e custos de transação. 0 livro traz uma característica distintiva ao inserir a antropologia (cultura) e a ciência política (poder e conflito) no âmbito da sociologia econômica.

THE HANDBOOK OF ECONOMIC SOCIOLOGY. Neil J. Smelser e Richard Swedberg (editores). Princeton: Princeton University Press, 1994.835 p.

Este livro traz um quadro abrangente da produção acadêmica norte-americana em sociologia econômica. São apresentados 31 temas que tratam, entre outros, de cultura e economia, mercado como estruturas sociais, trabal ho e lazer. Cada tema foi desenvolvido por destacados especial istas, tais como Oliver Williamson (custos de transação e teoria organizacional), James Coleman (escol ha racional) e Mark Granovetter (grupos de negócios). A principal qualidade da obra é a de sistematizar, sem perder em profundidade analítica, o conhecimento al cançado pelos principais trabal hos de Sociologia Econômica e contribuir para a el aboração de novas linhas de pesquisa.

\section{ECONOMICS AND SOCIOLOGY - REDEFINING THEIR BOUNDARIES: Conversations with Economists and}

Sociologists. Richard Swedberg. New Jersey: Princeton University Press, 1990. $361 \mathrm{p}$.

0 autor realiza entrevistas com o objetivo de promover a interlocução entre economistas e sociólogos e fazer com que os pontos de interseção entre os dois campos de conhecimento sejam repensados. Foram entrevistados os pioneiros na área de sociologia econômica, tais como K. Arrow, A. Hirschman e N. Smelser. Por ocuparem posição central e estratégica no debate atual, foram entrevistados $\mathrm{G}$. Becker, J. Coleman, M. Granovetter e O. Williamson. Com o intuito de levantar questões sobre as novas interações entre a sociologia e a economia, a obra finaliza com os entrevistados A. Sen e J. Elster.

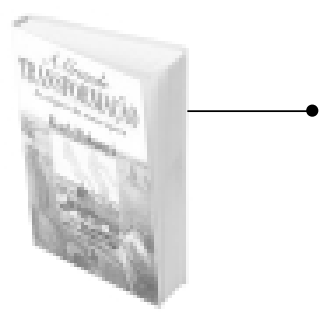

A GRANDE TRANSFORMAÇÃO: AS ORIGENS DA NOSSA ÉPOCA. Karl Polanyi. Rio de Janeiro: Campus, 2000. 349 p. O foco central dessa obra são as origens econômicas e políticas do desmoronamento de quatro instituições fundamentais do século XIX: o equilíbrio de poder entre os países dominantes, o padrão ouro, o estado liberal e o mercado auto-regulável. Utilizando-se das contribuições da história, antropologia e economia política, Polanyi mostra como o mercado se autonomizou em relação às demais instituições sociais, e as implicações sociais geradas por essa separação. 0 autor conclui que a moderna economia de mercado, ao transformar a terra, o trabalho e o dinheiro em mercadoria, revela seu caráter destrutivo e dominador da sociedade.

SAÍDA, VOZ E LEALDADE: REAÇÕES AO DECLíNIO DE FIRMAS, ORGANIZAÇÕES E ESTADOS. Albert Hirschman.

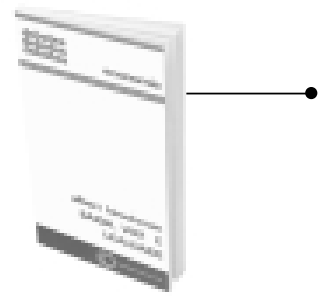

São Paulo: Perspectiva, 1973. 147 p.

0 autor tem por objetivo explicar como os indivíduos reagem às mudanças ou à deterioração do desempenho das organizações e do Estado. Para isso, Hirschman propõe as categorias "saída" (mecanismo de mercado), "voz" e "leal dade" (mecanismos de não mercado), e expõe a dinâmica segundo a qual esses mecanismos, partícipes tanto de empresas quanto de órgãos públicos, interagem ou se excluem. Sob esse enfoque, o autor investiga questões como: que instituições servem para aperfeiçoar as opções "saída" e "voz" como mecanismos de recuperação; e se as instituições que aperfeiçoam a opção saída são compatíveis com as que melhoram a opção voz. 